\title{
TORNAR-SE PROFESSOR DE FRANCÊS NO BRASIL: A EXPERIÊNCIA DO PROJETO LES CRABES PARA A IMPLEMENTAÇÃO DE POLÍTICAS PÚBLICAS LINGUÍSTICAS
}

\author{
Joice Armani Galli/LENUFLE/UFPE \\ Lorena Santos/LENUFLE/Université Haute-Alsace
}

\begin{abstract}
RESUMO
Refletir sobre o ensino-aprendizado de línguas estrangeiras no Brasil implica discutir políticas linguísticas. Tal reflexão convida-nos a buscar uma articulação entre poder público, formação superior e sala de aula. Sob a perspectiva de língua enquanto prática social de interaçáo, o presente trabalho propóe-se a discutir projetos alternativos para a implementação de currículos plurais e inclusivos.
\end{abstract}

PALAVRAS-CHAVE: políticas linguísticas; línguas estrangeiras; francês

\section{Introdução}

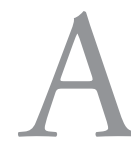

discussão acerca de políticas públicas linguísticas data de uma época recente em nosso país. Igualmente jovem é a reflexão sobre o processo de ensino-aprendizagem de línguas estrangeiras (LE) no contexto da escola pública. Nesse sentido, a proposta atual do Ministério da Educação e Cultura (MEC) sobre uma base curricular comum demanda atenção para o olhar crítico que a inserção deste campo do conhecimento implica. Igualmente criteriosa deve ser a reforma curricular exigida pelo Conselho Nacional de Educação (CNE), na Resolução número 2, de primeiro de julho de 2015, em que serão revistos os componentes curriculares a fim de delinear uma nova identidade às licenciaturas de todo Brasil. 
Por entendermos que reflexóes a respeito da temática curricular correspondam a açóes políticas de planejamento linguístico, organizamos o presente artigo sob três grandes eixos. Inicialmente pensamos que discorrer sobre instituições públicas, como espaço político de debate linguístico, seja oportuno para desenvolver o tópico seguinte, relativo à formação universitária e à sala de aula de LE no Brasil. Finalizaremos com o relato de experiência do projeto de francês Les Crabes (Os Caranguejos), como exemplo de alternativas viáveis para a inserção da LE na paisagem cultural pública brasileira.

\section{Instituições políticas e debate linguístico}

As discussóes acerca da temática sobre implementação de políticas públicas linguísticas em LE têm sua incipiência desde a formação universitária e passam pelo poder e vontade políticos, até chegarem à sua mise en scène, que é a sala de aula da rede básica de educação. No que tange à formação universitária, já tivemos modelos baseados na dupla licenciatura, e hoje muitas Instituiçóes de Ensino Superior (IES) optaram pela licenciatura única em LE, por entenderem como insuficiente o desenvolvimento de apenas quatro anos para alunos que ingressam com um niveau zéro en langue. De fato, discutir o tripé universitário formação, pesquisa e extensão sob uma ótica de que o professor de LE é um reprodutor de métodos, entenda-se aqui manuais, é certamente insuficiente para sua colocação no mercado de trabalho ao final do referido tempo. Insuficiente é também uma formação en double licence sem garantir um conhecimento minimamente aprofundado em língua portuguesa e na LE de sua escolha, contemplando os componentes solicitados pela nova reforma curricular das licenciaturas, a exemplo de direitos humanos. Portanto, urge que se repensem os objetivos da formação superior em LE dos cursos de Letras em todo o Brasil.

Entendemos, ainda, ser igualmente indispensável a discussão quanto ao perfil de estudante que se busca formar para atender o contexto multicultural e assoberbado de informaçóes que caracteriza a sociedade atual. $\mathrm{Na}$ formação universitária, a dificuldade maior parece repousar no desafio de transformar informação em formação e, por conseguinte, em conhecimento.

De qualquer maneira, percebe-se que o problema do ensino superior não está no modelo, mas no conceito que se tem do futuro profissional de LE, inserido no contexto contemporâneo de sua formação. É preciso que se crie o 
mercado, é preciso romper com práticas metodológicas tradicionais, é preciso fugir à lógica utilitarista das línguas. Do contrário, o mercado de trabalho continuará sendo insuficiente para a atuação de profissionais em LE, e em particular em francês como língua estrangeira (FLE).

Temos uma démarche institucional ainda muito voltada para o resultado de mera informação, e não para o fruto efetivo da formação (estando ainda, portanto, muito vinculada a uma forma de reprodução do conhecimento, e não de sua produção). Tal constatação pode ser observada na maneira como as LE estão presentes em grande parte de políticas nacionais ${ }^{1}$. Partindo da noção de língua como interação, existindo, portanto, em um processo social, como fator ideológico que determina e é determinado pela sua forma de expressão, consideramos oportuna a afirmação de Almeida, ainda que relativa à língua portuguesa:

A língua é produzida socialmente. Sua produção e reprodução é fato cotidiano, localizado no tempo e no espaço da vida dos homens: uma questão dentro da vida e da morte, do prazer e do sofrer. Numa sociedade como a brasileira - que, por sua dinâmica econômica e política, divide e individualiza as pessoas, isola-as em grupos, distribui a miséria entre a maioria e concentra os privilégios nas mãos de poucos, a língua não poderia deixar de ser, entre outras coisas, também a expressão dessa mesma situação. (ALMEIDA In: GERALDI, 2002, p. 14)

Consideramos tal reflexão pertinente por reverberar nas discussóes atuais sobre ensino-aprendizagem de LE. Processo ainda concebido como objeto de elite pela sociedade brasileira, a política de inserção das línguas no currículo escolar continua a ser um assunto muito delicado, il s'agit d'un sujet sensible. Certamente a abertura para a mobilidade estudantil, experimentada nos últimos anos, é um indicativo de que o processo de ensino-aprendizagem de LE está sendo revisto. No entanto, há ainda muito a ser feito.

Apesar da existência de estudos de mestrado e doutorado que atentem para a importância da formação em pesquisa através do processo desencadeado pelo conhecimento das LE, a exemplo da investigação de Galli (2004)

1 Sobre este assunto, sugerimos a leitura do artigo de Aubin \& Galli (2015), em que há o levantamento sobre o estado de arte da língua francesa nas escolas públicas de Olinda e Recife. 
quanto à proficiência de francês no estado do Rio Grande do Sul, somente a implementação de políticas públicas é que vem assegurar seu reconhecimento. É o caso do programa Ciências Sem Fronteiras (CsF), responsável por trazer à cena um aspecto nuclear da formação universitária: o conhecimento das línguas para o desenvolvimento dos estudos acadêmicos.

Foi assim que, em 2012, por iniciativa dos reitores das universidades federais brasileiras, criou-se o programa linguístico Inglês sem Fronteiras - IsF, vinculado ao CsF. Logo após, deu-se a inclusão de outras LE, entre elas o francês, no então nomeado Idiomas sem Fronteiras (IsF), que aproveitava, assim, a sigla do programa linguístico que o precedera.

Discorrer sobre o emprego de "sem fronteiras" em um mundo globalizado, mas cada vez mais entrincheirado, é tema para outro artigo; aqui, restringimo-nos à observação valorativa da expressão. Da mesma forma, não pensamos ser o presente texto o espaço para discussão acerca do entendimento de que não se trata somente de uma língua estrangeira, mas de algo que passaria a incorporar o sistema linguístico do sujeito, configurando-se como língua adicional. Esse, também, é tema para outra discussão, já que entendemos que a adição não elimina o estranhamento de um saber que vem a multiplicar-se (GALLI, 2014). Para tratarmos efetivamente de adição seria preciso considerarmos a aquisição de línguas desde a Educação Infantil, o que seria aliás formidável para todo o processo cognitivo nessa faixa etária. Sendo assim, optamos por nos referir aqui a lingua estrangeira (LE) por respeito ao seu cunho de estranheza, de distinção, de diversidade e pelas implicaçóes recíprocas que estabelecem em relação à alteridade e ao intercultural, noçóes subjacentes à formação de cidadãos do mundo, sob uma perspectiva positiva de globalização. A nosso ver, não será a questão da nomenclatura que determinará a efetiva adoção do ensino-aprendizagem de LE nas escolas públicas, mas a discussão dos propósitos que a envolvem; por tal razão, ratificamos a opção pelo emprego de LE, porque mais adequado e contextualizado à realidade brasileira.

Encerrando a digressão sobre as nomenclaturas "sem fronteiras" ou "língua estrangeira", voltemos para a consideração maior acerca do programa IsF: a tomada de consciência, positiva e relativamente recente, quanto ao entendimento de LE como formadora de cidadãos. É dessa forma que entendemos a iniciativa do referido programa e a própria discussão sobre o tema das "línguas estrangeiras/adicionais" na rede pública brasileira. 
Cabe ressaltar que, juntamente com o processo de implementação do programa linguístico IsF, a década anterior foi brindada com a discussão dos Parâmetros Curriculares Nacionais (PCN), os quais remetem à época de um governo precedente, mas que deixou suas marcas através da reflexão que se faz até o presente sobre parâmetros que chegam a ser confundidos com legislação. Muitos trabalhos em nível de pós-graduação e mesmo trabalhos de conclusão de curso (TCC) foram e ainda são pautados pelas reflexôes oriundas desse guia para políticas educacionais no Brasil, que marcou o início dos anos 2000. São frutos dessa discussão o olhar sobre a importância de se trabalhar os gêneros na escola $^{2}$ e a pertinência da sensibilização a uma LE ainda na Educação Básica. Hoje, no entanto, fala-se de uma Base Nacional Curricular Comum (BNCC), a qual deve dar continuidade às conquistas anteriores da educação.

Tais perspectivas convidam igualmente a pensar sobre a legitimidade da Lei de Diretrizes e Bases da Educação Nacional (LDBEN no 9394/96), que garante a oferta ${ }^{3}$ de uma LE a partir do Ensino Fundamental, nos anos finais, e dispóe sobre a obrigatoriedade do espanhol no Ensino Médio, promulgada pela Lei ${ }^{\circ} 11.161$ de 2005. A importância de ambas é indiscutível; mas, se tais legislaçóes não conseguiram assegurar o papel das línguas na escola pública, isso significa que o diálogo entre formação universitária e instituiçôes de ensino resta ainda insuficiente. De fato, positivo é que tais legislaçóes tenham trazido à discussão a relevância do ensino-aprendizado de LE na formação humana e, sublinhamos aqui, humana, e não humanística, porque este termo remeteria a outra época, com representaçóes linguísticas diversas das nossas, já que [...] antes mesmo de estrutura, a língua é por natureza conceito seja pelo conjunto de valores que agrega, seja pela representação que evoca. (GALLI, 2015, p. 117).

Nesse contexto, a universidade tem o papel de, mais do que apenas problematizar o ensino-aprendizado de LE, ser um espaço de reflexão e ação propositivas. Assim, além de discutir as dificuldades intrínsecas ao processo de inserção de políticas públicas linguísticas, pode e deve fomentar a criação de ambientes para o acontecimento da aula de línguas na Educação Básica, sob o viés do diálogo prazeroso e libertário que a interação linguística com o outro favorece.

2 Para mais informaçóes sobre o gênero oral debate, sugere-se a leitura de ARAÚJO, 2016.

3 Registre-se, quanto ao uso do termo "oferta", seu viés explicitamente capitalista, impregnado na lógica de mercado relativo à inserção das LE na educaçáo pública brasileira. A partir daqui, empregaremos vocábulos mais coerentes com a proposta que sustentamos, tais como "oportunidade", "promoção" e "possibilidade". 
Vale lembrar que, ao fato de a discussão acerca das LE no espaço público ser ainda recente, soma-se a insuficiência na sustentação de políticas implementadas não somente de forma vertical, mas nascidas da base, dos professores, dos alunos, dos pais e dos funcionários que fazem o cotidiano da escola. Então, se hoje é proposto que se repensem projetos de $\mathrm{LE}^{4}$, observamos que a maior dificuldade que enfrentada ainda é a falta de articulação entre poder público, formação universitária e sala de aula ${ }^{5}$.

Sob tal perspectiva surgiu o projeto Les Crabes, articulando formação universitária, pesquisa e extensão ao criar um espaço de discussão do ensino-aprendizado de LE - no caso, do francês. A proposta, ainda circunscrita ao ambiente educacional, ultrapassa os muros da escola para a efetivação do tripé universitário, através da vontade política de uma comunidade imbuída de seu poder público, enquanto instância maior para o debate linguístico.

Assim, o capítulo a seguir trata do exercício universitário de articulação entre os pilares acadêmicos para o fomento à produção de projetos pedagógicos alternativos, concebidos sob a ótica do letramento em LE como prática social. Posteriormente, apresentaremos a criação do referido projeto de língua francesa Les Crabes, voltado para uma biblioteca comunitária de Recife. Finalizaremos com o relato dessa experiência pela voz de sua idealizadora, para então propormos algumas considerações finais sobre as açôes de política e planejamento linguísticos.

4 Somente para citar, mencionamos o projeto de língua inglesa Ganhar o Mundo, da Secretaria de Educação do Estado de Pernambuco; a implantação do espanhol, cuja obrigatoriedade apenas no final da Educaçáo Básica e a carga horária reduzidíssima têm sido questionadas; e ainda projetos mais tímidos, como o Francês Cantado pelas Crianças em uma escola municipal da rede pública de Recife (AUBIN ET AL, 2014).

5 Obviamente a escola popular não corresponde muitas vezes aos interesses sociais mais conservadores, já que o despertar para o processo de LE redimensiona o pensamento, conforme o vivido em uma sala de aula dos Anos Iniciais do Ensino Fundamental. Durante uma aula de francês em que se ensinava o emprego do gênero feminino e masculino das nacionalidades, a fim de possibilitar uma associação, buscou-se mostrar a semelhança entre essa noção também na língua portuguesa. Assim, se temos français e française, qual seria o feminino de português? Face à resposta de que não seria outro senáo a matemática, concordamos com o aluno que identificou o fato de que somente esses dois componentes curriculares - o português e a matemática - são realmente importantes em um modelo de escola tradicional. Para maiores considerações acerca do trabalho de LE com crianças, sugere-se a leitura de Rochebois, 2014. 


\section{Formação, pesquisa e extensão universitárias}

Por acreditarmos que a experiência da descoberta engendra no sujeito condições para sua transformação é que apostamos na realização de ações de política e planejamento em LE. A dinâmica investigativa promovida pela reflexão linguística nas licenciaturas em Letras, no Brasil, reacende um conceito clássico das ciências modernas, pois, como afirma Paviani:

O fazer científico articula, ao mesmo tempo, o conhecimento, a linguagem e a realidade, no nível da ação e no nível da representação. A investigação desse fenômeno unitário, linguagem-conhecimento-realidade pode ser analisada, ora sob o enfoque do conhecimento, ora da linguagem, ora da realidade; porém, o que náo pode é perder de vista a unidade que sustenta o fenômeno. (PAVIANI, 2013, p. 18)

Destacando-se essa unidade científica e a formação universitária, entendemos que o vir a ser, implícito no 'tornar-se professor de línguas', em nosso título, é um contínuo na vida profissional, pois sua formação permanente é condição sine qua non para o exercício pleno de suas atividades - algo exigido talvez mais nesta área do que em qualquer outra, dada a questão da alteridade subjacente ao binômio língua-cultura. Neste artigo, damos evidência ao trabalho do professor de LE da rede pública da Educação Básica, à existência de um grupo de pesquisa de língua francesa, o LENUFLE - Letramento 'Numérique' do Francês como Língua Estrangeira ${ }^{6}$-, e ao aluno de licenciatura em Letras, que entende o fazer pedagógico como modalidade do conhecimento, fortalecendo a tríade sugerida por Paviani (2013) no fenômeno evocado anteriormente.

Situados, assim, sobre o papel social da língua, evocamos o teórico Bakhtin (1984), que, importa registrar, não discorreu sobre o contexto da sala

6 Cabe aqui comentar que o conceito inicialmente adotado sobre letramento pelo referido grupo de pesquisa teve sua base em teóricos como Magda Soares e Luiz Antônio Marcuschi, que postulam o letramento como prática social exclusivamente da ordem do escrito. No entanto, o desenvolvimento de trabalhos com o francês expandiu a noção também para os aspectos relativos à oralidade em LE, já que fala e escrita circunscrevem-se às modalidades de uso da língua, diferentemente de oralidade e letramento concebidos como práticas sociais, indo ao encontro do conceito de letramento em LE adotado pelo grupo de estudos franceses. 
de aula em nenhuma de suas publicações, mas desenvolveu reflexões que entendemos ser relevantes para a discussão contemporânea sobre ensino-aprendizagem de LE. Segundo o referido teórico, é capital refletir quanto ao papel da interação nos estudos relativos às linguagens. Tendo Bakhtin preconizado a distinção entre as ciências exatas e humanas, favoreceu importantes empreendimentos investigativos na linguagem, e valemo-nos de seu postulado para mergulhar na proposição de metodologias para a pesquisa e formação em LE. De fato, se há nas ciências duras um objeto que será explicado, temos, em contrapartida, na esfera das ciências moles, um fenômeno a ser compreendido. Daí a pertinência de uma questáo frente à qual se confrontam os membros do grupo de pesquisa LENUFLE da Universidade Federal de Pernambuco (UFPE): um bom pesquisador/professor é o que age tecnicamente ou o que atua participativamente? Perspectivados sob a ótica de que o sujeito se constitui na interação com o outro, somos inclinados a optar pela segunda alternativa. E nessa lógica percebemos o lugar de ação e planejamento para políticas públicas proativas, a exemplo do projeto Les Crabes, o qual apresenta forte fundamentação nos princípios orientadores da Linguística Aplicada (LA).

Tendo surgido no meio do século passado, a LA chegou ao Brasil de forma silenciosa, sendo conhecida incialmente pelo cunho aplicacionista da então subárea da Linguística. Esta, sim, grafada com letra maiúscula, porque de base mais teórica, ecoava as prerrogativas da escola estruturalista, tâo presentes ainda hoje no ensino-aprendizado de LE. Entretanto, o caráter social fez com que aspectos fronteiriços da LA fundassem um campo de investigação mais autônomo, conforme sugere Moita Lopes (2009) acerca da emancipação e atualidade dessa ciência contemporânea.

Além de Moita Lopes, não há como evocar a presença da LA nas pesquisas linguísticas brasileiras sem mencionar outro nome central desse campo do saber: Alba Celani. A estudiosa (e referimo-nos aqui em especial ao seu texto de 1998) aborda a natureza plural com a qual foi se delineando a LA até atingir sua maturidade acadêmico-científica enquanto saber transdisciplinar nas últimas décadas. Exemplo disso são os trabalhos que circulam no território nacional e que bebem dessa fonte para proceder à metodologia da pesquisa em LE.

A esse respeito, e por relatarmos posteriormente um projeto alternativo de ensino de francês que sai da fronteira da universidade, atravessando muros e criando pontes efetivas de ação e planejamento linguísticos, nos valemos de 
Araújo (2016), citando-o quanto ao resgate da LA no Brasil:

[...] estava claro que a LA, no percurso de sua investigação, atuava como articuladora de diversos domínios do saber, em diálogo intenso com diversos campos que, de algum modo, preocupamse com a linguagem. Diante desse cenário, os linguistas aplicados percebem que estão, frequentemente, indo por caminhos diferentes, muitas vezes, dos percorridos durante o período de sua formaçáo inicial [...], pois se dáo conta de que necessitam ir à procura de explicaçōes para os fenômenos que pesquisam em outros campos do saber que necessariamente podem não estar ligados ao campo da linguagem no sentido estrito. (ARAÚJO, 2016, p. 24)

O capítulo a seguir situa-se justamente nesse contexto, pois traz em seu bojo a coerência epistemológica da pesquisa social, a exemplo da ação extencionista Les Crabes. Sob a perspectiva de que formação, pesquisa e extensão devem andar juntas como responsabilidade social na formação de formadores, escopo final da vida universitária nas licenciaturas, sustentamos a discussão em torno do letramento em LE como prática social e sua estreita partilha em relação à fluidez das fronteiras sugerida pela LA. O entendimento de que a polarização saussuriana langue x parole legou uma herança dual para os estudos da linguagem e, particularmente, para os estudos de base linguística nas LE é inegável; por isso, é preciso reinventar a sala de aula de LE e os projetos que a ela possam vir a se vincular.

Rompendo com a ótica positivista de ensino de línguas e buscando o trabalho com a linguagem através de sua fenomenologia é que se concebem os projetos de pesquisa e extensão do laboratório de francês LENUFLE. Nesse sentido, a LA veio a embasar a reflexão do projeto social dos caranguejos como letramento em LE, além de respaldar academicamente grande parte dos membros que se encontravam ainda em plena formação, ou seja, desenvolvendo seus estudos em nível de graduação.

As condições de produção, que sabemos serem determinantes para açóes linguísticas, foram também contempladas pelo que Geraldi (2010) nomeia como "trabalho linguístico", sendo oportuno citá-lo, já que teremos no referido projeto uma troca de correspondências que faz de cada aluno sujeito discursivo, autor de sua história. 
O deslocamento da noção de representação para a noção de trabalho linguístico exige incorporar o processo de produção de discursos como essencial, de modo que náo se trate mais de aprender uma língua para dela se apropriar, mas trata-se de usá-la e, usando-a, apreendê-la. (GERALDI, 2010, p. 153, grifo nosso)

Dessa forma, consideramos pertinente apresentar o relato de letramento do projeto Les Crabes (cujo nome estabelece uma relação com o cultivo do caranguejo), que se insere tanto na comunidade acadêmica quanto na comunidade de sua origem, às margens do mangue. Para tanto, subdividimos o terceiro item de nossa proposta de artigo em: panorama histórico do projeto, contexto social da pesquisa, além da biblioteca propriamente dita e o trabalho específico com cartas na sala de aula de francês.

\section{Les Crabes - trajetória de 2009 a 2016}

Não há como relatar o projeto sem mencionar inicialmente as difíceis condiçóes de produção que o circunscreveram, seja na universidade, seja na comunidade. Ouve-se muito em bancas de TCC, mestrado e doutorado que a academia está ultrapassada; pois predicativos como jurássica e conservadora fazem jus à dificuldade que foi registrar tal projeto. Fala-se muito sobre a modernidade que a universidade brasileira deve promover, mas na prática é bastante complicado propor projetos alternativos como esse.

Tal dificuldade institucional surge de outra dificuldade ainda maior: a realidade social em que a comunidade popular da Ilha do Retiro está inserida. Sob condiçóes bastante adversas, o projeto contou com a iniciativa da entáo aluna de licenciatura Letras-Francês da UFPE, Lorena Santos. Foi no ano de 2011 que se deu início ao trabalho de língua francesa na Biblioteca Comunitária Caranguejo Tabaiares (BCCT).

Considerando-se as primeiras dificuldades, o registro e reconhecimento da relevância desse projeto, seu primeiro ano foi caracterizado pelo processo de sensibilização linguística introduzido ao grupo de usuários da BCCT. Nesse sentido, vale a pena recuperar um breve traçado de como surgiu esse projeto, cujo objetivo principal é o de proporcionar às crianças e aos jovens frequentadores desse espaço a oportunidade de aprender francês. 
A proposta inicial foi pensada a partir de um contrato institucional já existente, feito em 2009 por ocasião do Ano da França no Brasil, entre as prefeituras de Recife e Nantes. A parceria entre as duas cidades, que são consideradas villes jumelles por causa de seus rios e pontes, aproximou a BCCT do projeto Nantes lit dans la rue, realizado pelo Atelier $d u 147$. O intercâmbio possibilitou a troca de cartas, e-mails e videoconferências entre as duas comunidades, mas a falta de conhecimento do português, por parte dos franceses, e do francês, por parte dos brasileiros, afastou e dificultou a comunicação entre ambas as cidades.

\section{Contexto social}

A comunidade Caranguejo Tabaiares é considerada uma das favelas mais pobres de Recife, localizada às margens do Rio Capibaribe. Os moradores sofrem com a falta de saneamento básico e com a má qualidade de habitação. $\mathrm{O}$ mesmo rio que garante o sustento de muitas famílias através da criação de camarôes e caranguejos também é o responsável por trazer quase metade do lixo (40\%), que fica acumulado nos viveiros, becos e casas. Os outros $60 \%$ do lixo são produzidos pela própria comunidade, que também sobrevive deles, por meio da catação e reciclagem. A seguir, podemos observar algumas fotografias feitas para o conhecimento do campo de atuação do projeto, já que estávamos na etapa relativa à analyse $d u$ terrain, conforme orientam Blanchet \& Chardenet (2011) acerca de abordagens contextualizadas para realizaçáo de projetos linguísticos. Tais fotos ilustram um pouco da realidade na qual estão inseridos nossos alunos até os dias atuais.
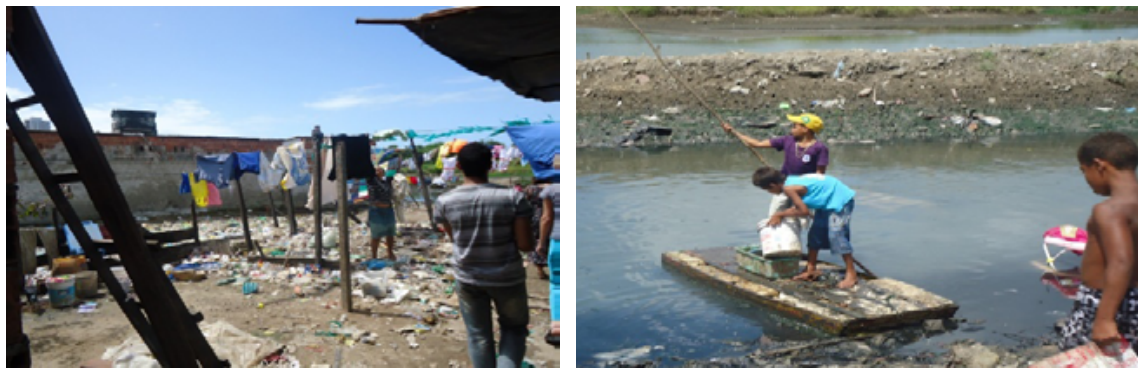

Imagem 1: Frente de uma das casas às margens do Rio Capibaribe (crédito: Lorena Santos). Imagem 2: Crianças em busca de caranguejos (crédito: Lorena Santos).

7 Na época, o site do projeto francês noticiou a parceria, como se pode verificar no link http:// atelier14.net/nanteslitdanslarue/?cat=71 
A partir dessas imagens, percebemos a negligência de noções básicas de saúde e educação. $\mathrm{O}$ conformismo é visível em muitas famílias, que criam seus filhos misturados aos animais e à sujeira, sem qualquer condição de higiene. $\mathrm{Na}$ segunda imagem, observamos crianças navegando sobre o canal que é despejado em um dos braços do rio Capibaribe.

Quando a maré está alta, os caranguejos invadem os becos da comunidade; quando está baixa, os adultos e crianças vão apanhá-los no mangue. Daí a inspiração para o nome do nosso projeto Les Crabes, que busca "invadir" a comunidade com uma alternativa de inclusão social através da língua francesa.

\section{A biblioteca}

A Biblioteca Comunitária Caranguejo Tabaiares (BCCT) foi criada a partir da iniciativa de Cleonice Silva e de cinco jovens, todos moradores da comunidade. Esse espaço de apenas $6 \mathrm{~m}^{2}$, que até hoje está sob os cuidados dessa senhora, existe desde 2005 e teve o importante apoio inicial da universidade estadual de Pernambuco (UPE) na doação de livros e também na profissionalização dos primeiros mediadores da Biblioteca. Atualmente, a UFPE tem contribuído com a elaboração do programa pedagógico do projeto, tornando profícua tal colaboração ao articular os pilares sobre o qual se sustenta o conhecimento acadêmico-científico.

Como mencionado anteriormente, a prefeitura do Recife assinou convênio com a cidade de Nantes, tornando-as cidades gêmeas. Para firmar essa parceria, Nantes enviou um jovem francês a fim de ajudar nas articulações entre as duas prefeituras. Ao conhecer a Biblioteca, passou a incluí-la nas atividades do intercâmbio cultural que o convênio propunha, estabelecendo assim uma parceria entre a BCCT e o Atelier du 14 . O projeto que existe na cidade de Nantes propóe às crianças e aos jovens de um bairro carente (Malakoff - $\mathrm{n}^{\mathrm{o}}$ 14) o acesso à leitura através de uma biblioteca de rua, daí seu nome Nantes lit dans la rue. Desde então, a BCCT passou a ter um projeto de intercâmbio cultural e linguístico que proporciona até hoje a troca de cartas, informaçóes sobre metodologias, estratégias e resultados, beneficiando tanto as crianças quanto os mediadores de ambos os países. É por esse motivo que a Biblioteca assume o papel de centro cultural para aqueles que só têm como opção de lazer, em seu bairro, uma igreja. 


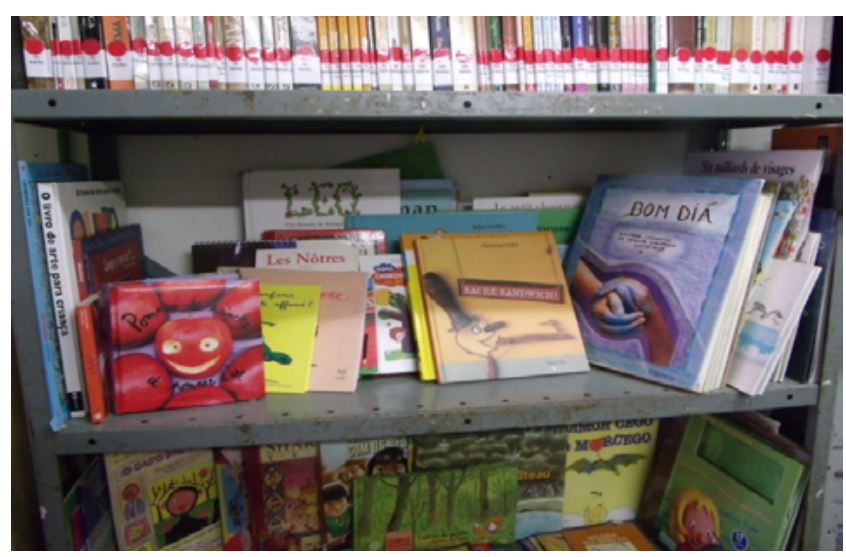

Imagem 3: Acervo de livros franceses doados por Nantes (crédito: Lorena Santos).

A necessidade de ler, de dar voz às cartas, aos e-mails e aos livros tornou-se cada vez mais evidente para a continuação da parceria, principalmente quando se tratava de colocar em prática as solicitaçóes do Atelier $d u$ 14, como propor atividades, compartilhar experiências e dificuldades. Ainda no início do convênio entre Nantes e Recife, os jovens da comunidade tiveram aulas de francês na Aliança Francesa, mas essas aulas só duraram um ano (2010). Infelizmente tal tentativa foi frustrada, inicialmente pela insuficiência institucional de dar continuidade ao projeto e, por fim, por causa do "choque cultural" entre o público que frequentava a escola e os jovens da Biblioteca, que vestiam suas melhores roupas para ir às aulas. Além disso, eles dependiam de um transporte oferecido pela prefeitura de Recife, que os levava da comunidade até o curso de francês. Esse transporte quase sempre chegava após o horário da aula ou simplesmente os esquecia.

Todos esses fatores foram analisados e levados em conta para efetuação do projeto pedagógico e linguístico. Porém, frente à saída da aluna pesquisadora para realizar estudos na França, em 2014, o projeto teve de ganhar continuação por meio da chamada de novos graduandos. Lamentavelmente a procura foi reduzida, mas encontramos um jovem pesquisador disposto a dar continuidade às atividades.

Assim, de 2015 até a atualidade, o projeto conta com o auxílio de Artur Rodrigues, aluno formando de Letras-Francês da UFPE, tendo sido redimensionado através do nome Les Crabes II. No início, foi igualmente oportuno 
termos a participação de outra aluna também formanda, Rahisssa Lima, que, por ocasião do edital Mais Cultura lançado em dezembro de 2014, elaborou juntamente com a coordenação acadêmica do projeto uma proposta de fomento à ampliação física da BCCT. Apesar do resultado positivo, não foi viabilizada a verba até janeiro de 2016, quando optamos por retornar ao projeto com o caráter unicamente pedagógico, já que esta era mais uma entre as recusas de auxílio financeiro que já havíamos recebido. Cabe registrar que, além da colaboração dos dois novos alunos, foi possível contar a partir de março de 2016 com a colaboração acadêmica da professora Daniela Kunze, que passa a coordenar, juntamente com a equipe fundadora, o projeto então intitulado Les Crabes III. Passemos a seguir ao cerne deste trabalho, a partir do ponto de vista da professora Lorena Santos.

\section{A sala de aula do projeto les crabes - abordagem holística}

Considerando o survol historique apresentado anteriormente, centraremos este relato na perspectiva da sala de aula, por entender que a dinâmica impressa ao projeto é fonte fértil de trabalho linguístico, articulando linguagem, conhecimento e realidade. Assim, o projeto Les Crabes não se resume apenas ao exercício social de voluntariado desenvolvido em uma comunidade carente de Recife. Trata-se de um projeto de extensão e pesquisa que se propóe a ensinar a língua francesa para crianças e adolescentes por meio da literatura infantil. Tal projeto objetiva contemplar igualmente atividades propostas pelo intercâmbio cultural com a França.

Durante o primeiro ano de projeto, 2011, pudemos conhecer a comunidade, a biblioteca e os trabalhos ali desenvolvidos. Tivemos acesso aos livros e aos materiais doados pela associação Nantes lit dans la rue, além de cartas escritas pelas crianças de um bairro popular em Nantes. Assim, pudemos entender as necessidades e o que motivava as crianças, adolescentes e membros da Biblioteca a quererem aprender francês.

Pontualmente, são estas as razóes que fazem da BCCT um lugar em potencial para a criação e desenvolvimento do projeto Les Crabes: 1) Recebe diariamente uma média de 50 crianças entre 4 e 13 anos, que a visitam de forma voluntária; 2) Possui mais de 350 livros de literatura infantil e infanto-juvenil; 3) Independente das gestóes governamentais, o intercâmbio entre a cidade de 
Nantes e Recife, através da associação Nantes lit dans la rue e da BCCT, permanece até hoje; 4) As correspondências e os livros construídos pelas crianças francesas representam materiais autênticos escritos por personagens reais.

Apesar de contarmos com um espaço para a realização das aulas, com a presença de uma professora de francês (nesta época em formação) e de materiais didáticos, se fez necessário um apoio pedagógico e científico para o avanço das atividades. Passamos de um projeto meramente social para um projeto de extensão chancelado pela UFPE e acompanhado por um grupo de pesquisa. É importante ressaltar neste artigo que, após o reconhecimento do Les Crabes pela universidade, os trabalhos na Biblioteca tornaram-se notórios no meio acadêmico e também na área de ensino de francês para crianças. Podemos ainda acrescentar que os estudantes universitários que colaboraram no projeto e as crianças receberam certificados, legitimando o trabalho e estudo ali realizados. A parceria entre a biblioteca comunitária e a universidade potencializou o projeto de ensino de francês para crianças, além de abrir caminho para a pesquisa em literatura infantil de língua francesa. Hoje contamos com uma rede de voluntários que trabalham direta e indiretamente com o projeto de francês, a exemplo da Associação de Professores de Francês de Pernambuco (APFPE), a Alliance française e o Institut français de Recife.

\section{A sala de aula do projeto les crabes - abordagem analítica}

Porque quando eu estudo francês eu me sinto, assim, feliz. Jésse - 10 anos

Os primeiros contatos com o público foram essenciais para o planejamento das atividades e também para chamar a atenção da comunidade sobre a possibilidade de aprender francês. Através da etapa de introdução, pudemos ter uma noção do contexto social em que as crianças estavam inseridas, entender o porquê de muitas delas não serem motivadas pelos seus pais à leitura e a razão pela qual frequentavam a biblioteca enquanto não estavam na escola: podiam, assim, obter um reforço escolar "gratuito" ou simplesmente manterem-se ocupadas. Fez-se necessária uma série de atividades nomeadas les démarches de sensibilisation, a fim de despertar o interesse em aprender francês; somente com elas daríamos sentido ao intercâmbio existente, além de torná-lo público para os próprios moradores da comunidade em nosso exercício de letramento em LE. 
Tínhamos razóes suficientes para iniciarmos um projeto de ensino-aprendizagem de línguas na comunidade; contudo, era preciso despertar o interesse pelo francês, já que ele não é ensinado nas escolas públicas de Recife. Além disso, as crianças não sabiam diferenciar o francês do inglês ou do espanhol, apesar de estas LE constarem no currículo das escolas públicas. Realizar o projeto de língua francesa seria um ato de respeito à comunidade, principalmente por sua inscrição em um intercâmbio internacional, como também representaria a "desconstrução” de um conceito glamoroso dado à língua francesa, como explica Galli:

Toda e qualquer língua LE não deveria acontecer em seu quadro educativo somente para fins lúdicos, mas também pelo respeito aos alunos, às suas famílias, enfim às comunidades das esferas de ensino públicas, pois a todos cabe o direito de aprender esta e outra LE, no entendimento do que sejam políticas públicas linguísticas. $\mathrm{O}$ viés plurilinguista deste trabalho busca, assim, a não fragmentação do saber pela hegemonia de uma ou outra língua. $\mathrm{Na}$ esfera pública, ensinar línguas não deve ser um exercício elitista do conhecimento, mas a possibilidade de viver dignamente como sujeitos de um mundo globalizado, através da educação pela linguagem. (GALLI, 2011, p. 20)

Em 2012 e 2013, propomos aos alunos essa possibilidade de descoberta do francês, valendo-nos da leitura de livros infantis e da redação de cartas a serem trocadas entre as crianças de Nantes e Recife. Além da produção de materiais para o intercâmbio, algumas atividades de língua francesa que apresentaremos neste artigo foram usadas estrategicamente para chamar a atenção do público e, consequentemente, colocaram em evidência o projeto Les Crabes e os materiais disponíveis na Biblioteca. Desde o início do projeto até os dias atuais, vários materiais foram recebidos e enviados para a associação Nantes lit dans la rue. Os que eram enviados pela Biblioteca representavam um tipo de resposta às dúvidas e perguntas escritas nos materiais criados pelos mediadores e pelas crianças de Nantes.

Em 2014, O Pássaro, ou L'oiseau, foi um dos trabalhos elaborados pela associação francesa. Nele, as crianças expressaram as suas dúvidas sobre os brasileiros e, junto com os mediadores da associação, desenharam um pássaro. No Brasil, as 
crianças da comunidade receberam $O$ Pássaro com bastante curiosidade. Nesse dia, fizemos uma atividade de introdução com aproximadamente 30 crianças em um espaço de $6 \mathrm{~m}^{2}$. Lemos as perguntas escritas em francês, e algumas palavras consideradas transparentes entre o francês e o português facilitaram a compreensão dos enunciados pelas crianças, sem a necessidade de traduzi-las. Destacamos dez perguntas e respostas a fim de exemplificar como foi realizada tal tarefa:

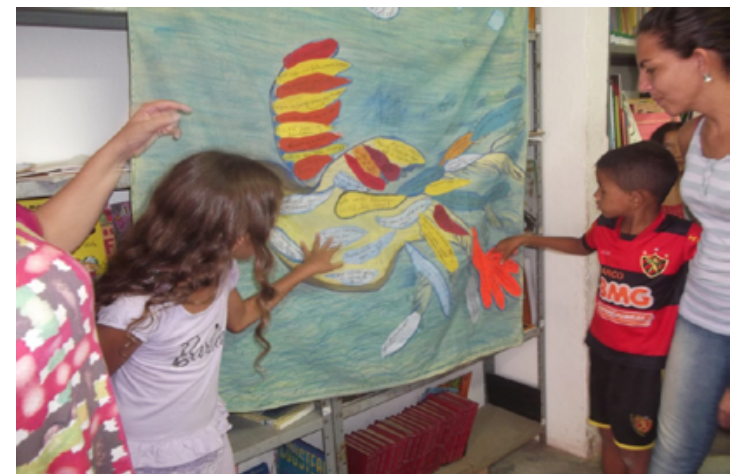

Imagem 4: Apresentação de O Pássaro às crianças da comunidade brasileira (crédito: Lorena Santos)

\begin{tabular}{|l|l|}
\hline \multicolumn{1}{|c|}{ PERGUNTAS } & \multicolumn{1}{|c|}{ RESPOSTAS } \\
\hline 1. D'où venez-vous? & $\begin{array}{l}\text { Da minha casa, de Recife, de Pernambuco, do } \\
\text { Brasil. }\end{array}$ \\
\hline $\begin{array}{l}\text { 2. Est-il vrai que les enfants travaillent pour } \\
\text { gagner de l'argent? }\end{array}$ & $\begin{array}{l}\text { Sim, no sinal de trânsito vendendo flanela, } \\
\text { pipoca, picolé e limpando os vidros dos carros. }\end{array}$ \\
\hline 3. Que faites-vous comme travail? & $\begin{array}{l}\text { Arrumamos a casa, lavamos pratos e cuidamos } \\
\text { de nossos irmäos mais novos. }\end{array}$ \\
\hline 4. Est-ce que vous avez déjà vu une 'arara azul?? & Sim, no zoológico e nos filmes. \\
\hline $\begin{array}{l}\text { 5. Où dormez-vous? Dans une maison ou dans } \\
\text { une cabane en bois? }\end{array}$ & $\begin{array}{l}\text { Na minha casa de tijolos. Mas o meu tio dorme } \\
\text { em uma casa de madeira. }\end{array}$ \\
\hline 6. Est-ce que vous avez un endroit pour jouer? & $\begin{array}{l}\text { Sim, na rua, em casa e em uma praça que tem } \\
\text { balanço e gangorra. }\end{array}$ \\
\hline 7. Est-ce que vous avez l'électricité chez vous? & Claro, mas às vezes falta. \\
\hline 8. Quels sont les oiseaux qui existent au Brésil?? & $\begin{array}{l}\text { Periquito, papagaio, sabiá, galo de campina, } \\
\text { beija-flor... }\end{array}$ \\
\hline 9. Comment est la vie au Brésil? & $\begin{array}{l}\hat{E} \text { boa porque temos uma familia, temos } \\
\text { brincadeiras e o que comer. É ruim porque } \\
\text { tem crianças que pedem esmolas, que não têm } \\
\text { família, que não estudam e que se drogam. }\end{array}$ \\
\hline
\end{tabular}

Tabela 1: atividade realizada no âmbito do projeto Les Crabes. 
Por meio de algumas perguntas e respostas, percebemos aspectos culturais como, por exemplo, na primeira pergunta, em que a criança que frequenta o projeto francês interroga: “De onde você vem? ” Para as crianças brasileiras, parece uma pergunta óbvia: elas respondem que vêm de suas casas. Mas, na verdade, essa questão revela que muitas das crianças, especificamente do bairro Malakoff, são imigrantes ou filhos de imigrantes na França. As demais perguntas mostram alguns falsos e/ou verdadeiros estereótipos existentes ou simplesmente mostram a curiosidade em descobrir outra cultura.

Do ponto de vista pedagógico, O Pássaro, além de servir como um exemplo de material autêntico, ou seja, construído por falantes nativos da língua e não necessariamente para fins didáticos, foi utilizado para introduzir assuntos gramaticais de forma lúdica e interativa como: la phrase interrogative en français; l'intonation; l'inversion du sujet et l'emploi de 'Est-ce que', sublinhados no quadro. A fim de desenvolver a referida atividade, elaboramos um vídeo e construímos um painel em forma de caranguejo que continha também algumas perguntas em português. Para construir os enunciados em francês, utilizamos as mesmas expressóes escritas pelas crianças francesas. Tanto o vídeo quanto o dito Caranguejo foram apresentados em julho de 2014, na cidade de Nantes, pela professora do projeto Les Crabes, conforme foto a seguir:

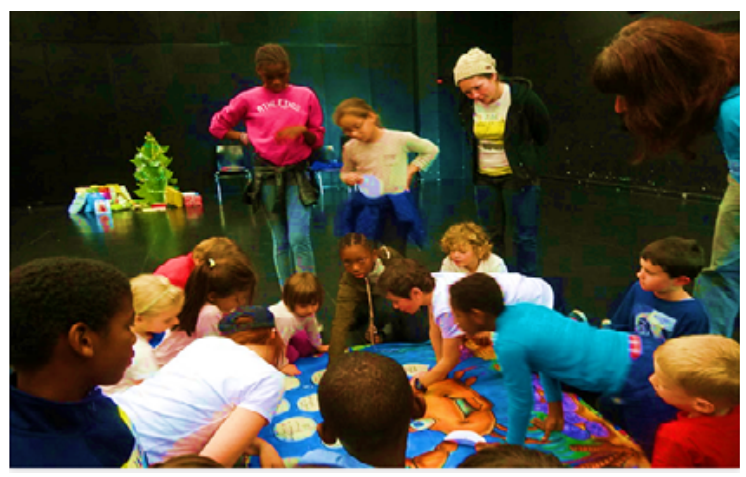

Imagem 5 - O Caranguejo e as crianças de Nantes (crédito: Lorena Santos).

A troca de correspondências e materiais estabeleceu um laço de amizade entre as crianças de Nantes e Recife. Foi na aula de francês que elas se conheceram e puderam reconhecer-se através da comunicação, através da descoberta da língua do outro. Ensinar uma LE onde existe necessidade de aprendê-la 
torna o processo mais interessante, produtivo e prazeroso para os alunos e para o professor, pois mantém a unidade científica entre linguagem, conhecimento e realidade. As crianças da BCCT são movidas pela curiosidade de descobrir o que existe por trás daquelas letras, palavras, frases e desenhos. São movidas a enxergar além do código linguístico, são movidas pela necessidade de comunicar, pelo entusiasmo em interagir com o outro.

A produção de materiais e cartas permitiu que os alunos praticassem a língua, percebendo as diferenças culturais intrínsecas aos sistemas linguísticos distintos. Em uma das cartas enviadas para a França, a aluna Kemilly Ferreira (11 anos) escreveu para sua correspondente, dizendo: Je me sens très heureuse de parler avec toi. Je t'aime. Esta mensagem foi recebida com surpresa pelos mediadores franceses e pela criança frequentadora do projeto francês, que logo revelou que nunca havia recebido carta com um "eu te amo". O aprendizado de uma língua faz com que o aluno coloque em prática todo um sistema linguístico e cultural até ali adquirido; além disso, permite expressar a sua realidade, seus desejos e sentimentos. As crianças são e devem ser vistas como sujeitos sociais atuantes e capazes de transmitir sua cultura e impactar o outro através da linguagem. O projeto Les Crabes compartilha a ideia de que língua não se resume apenas ao aprendizado para fins lúdicos ou profissionais, mas para estabelecer laços entre as pessoas e possibilitar diferentes leituras de mundo, criando pontes, transpondo barreiras, estabelecendo trocas "sem fronteiras", pelo próprio estranhamento que o conhecimento linguístico engendra.

O aprendizado do francês na Biblioteca é constituído tanto pelos ateliês de produção, que são as atividades para a confecção de materiais e correspondências, quanto pelas aulas de FLE que acontecem uma vez por semana, durante 2 horas. O planejamento e os exercícios pedagógicos são preparados e acompanhados pelo professor de francês e pelo coordenador do projeto. Essa parceria permite avaliar o andamento das atividades e o avanço no nível de aprendizado dos alunos. Até 2014, utilizávamos como material didático o método Amis et Compagnie 1, que nos ajudava a seguir um cronograma, além de oferecer documentos escritos e sonoros para o trabalho de compreensão oral e escrita. Contudo, com o passar do tempo a turma de francês passou a apresentar uma heterogeneidade, devido às diferenças de idade dos alunos. Foi assim que, a partir de 2015, dividimos a turma em crianças e pré-adolescentes e passamos a trabalhar com o método Tout Va Bien 1 para esse segundo grupo. 
Como já mencionado, o projeto conta igualmente com uma equipe de voluntários, como Luíza Motta, presente desde o início da ação extensionista, que trabalham diretamente na produção de materiais, leitura de livros em francês, deslocamento das crianças, entre outras atividades.

Desde 2014, a BCCT passou a ser um dos polos de comemoração da Semaine de la Francophonie em Pernambuco. Sendo umas das únicas instituiçôes a oferecer atividades exclusivas e gratuitas para crianças, sua programação francófona é divulgada anualmente junto ao cronograma oficial do Consulado da França em Recife. O projeto Les Crabes abriu portas para a prática didática de professores de francês em formação, em uma época escassa de oportunidades de estágio e de trabalho em Recife. Ofereceu, sobretudo, às crianças da comunidade Caranguejo Tabaiares, uma alternativa de educação e inclusão social através do aprendizado de uma LE, através do francês, língua da cidadania.

\section{Considerações finais}

Certamente um assunto táo polêmico e sensible como o proposto neste trabalho não tem a pretensão de encerrar conclusóes definitivas, mas algumas consideraçóes são passíveis de serem feitas. Uma delas diz respeito à necessidade de o trabalho linguístico fazer sentido na comunidade em que se insere, constituindo uma contribuição efetiva para a implementação de políticas públicas eficazes. Associada naturalmente a uma concepção de linguagem em LE, a qual considera que o professor difere de um mero reprodutor de métodos de língua, a presente reflexão propõe a construção não só de uma metodologia para pesquisa, mas principalmente de um entendimento mais dinâmico do trabalho linguístico que pressupóe a vivência da LE na escola pública, concebida assim na ótica do letramento em línguas.

Rompendo com o modelo positivista, promulgado pela bandeira nacional e existente ainda em alguns espaços de ensino, onde o que importa apenas são o ensino do português e da matemática, devemos pensar um currículo plural e diverso, seja na universidade, seja na escola ou na biblioteca. Devemos evitar modelos que se pautem pelo apagamento das diferenças e negação da diversidade linguística, pela globalização e pela escola neoliberal de sistemas públicos educacionais. 
O projeto Les Crabes invadiu e continua a invadir, dessa forma, também o plano das ideias e o horizonte de possibilidades que o processo de ensino-aprendizagem de LE desdobra. Trata-se do valor social e linguístico de seu conhecimento propiciado, neste relato de experiência, pela troca de cartas entre crianças francesas e brasileiras, para além do formato conteudista da sala de aula de línguas. Ao se mergulhar no estranhamento, multiplicam-se códigos, somam-se diferenças e ultrapassam-se fronteiras através da interação linguística, sugerida pelo processo de ensino-aprendizado libertador que implica o conhecimento de línguas estrangeiras.

\section{Referências}

ALMEIDA, Milton José. Ensinar português? In: GERALDI, João Wanderley (org). O texto na sala de aula. Sáo Paulo: Ática, 2002, p. 10-25.

ARAÚJO, Carlos Albuquerque de. Ensino e avaliação do gênero debate nos livros didáticos de português para o ensino médio aprovados no PNLD [Dissertação de Mestrado]. Recife: UPFE, 2016.

AUBIN, S., GALLI, J. Motiver à l'enseignement du français au Brésil. In: Le Français Dans Le Monde, n. 397 : 34-35, Janvier-Février. Paris: CLE International, 2015.

AUBIN ET AL. O ensino de Francês Língua Estrangeira nas escolas públicas: açóes para políticas linguísticas na rede municipal de Recife. Cadernos de Extensão da UFPE. Recife, 2014, https://www.ufpe.br/proexc/images/ publicacoes/cadernos_de_extensao/2014/cadernos_de_extensao_vol03.pdf , 25/02/2016.

BAKHTIN, Mikhail. Esthétique de la création verbale. Paris: Gallimard, 1984. BLANCHET, P., CHARDENET, P. (Orgs). Guide pour la recherche en didactique des langues et des cultures: approches contextualisées. Paris: Editions des Archives Contemporaines, Université de Rennes et Agence Universitaire de la Francophonie (AUF), 2011.

Base Nacional Curricular Comum: Línguas Estrangeiras, http://basenacionalcomum.mec.gov.br/\#/site/conhecaDisciplina?disciplina=AC_ LIN\&tipoEnsino=TE_EF, 11/09/2016.

BRASIL. LEI No 9.394, de 20 de dezembro de 1996. Estabelece as diretrizes e bases da educação nacional. http://www.planalto.gov.br/ccivil_03/leis/19394. htm22 abr. 2013. 
CELANI, M. A. A. Transdisciplinaridade na Linguística Aplicada no Brasil. In: SIGNORINI, I. \& CAVALCANTI, M. (orgs). Linguistica Aplicada e Transdisciplinaridade: questóes e perspectivas. Campinas: Mercado das Letras, 1998.

ESTADO DE PERNAMBUCO. Parâmetros para a Educação Básica do Estado de Pernambuco. Parâmetros Curriculares de Lingua Inglesa: Ensino Fundamental e Médio. Secretaria de Educação, 2013, http://www.educacao.pe.gov. $\mathrm{br} /$ portal/upload/galeria/4171/PCPE_VD_INGLES_EFM.pdf

GALLI, J. A. A noção de intercultural e o ensino-aprendizagem em línguas estrangeiras no Brasil: representaçóes e realidades do FLE. Revista UNESP Entrelínguas, v. 1, n. 1: 111-129, Sáo Paulo, 2015.

. Francês como Língua Estrangeira e como Língua Adicional: a diferença que multiplica. Revista Salto para o Futuro, v. Revitalização do Ensino de Francês no Brasil, maio de 2014, http://tvescola.mec.gov.br/tve/salto/publicacao;jse ssionid=8F87ECD27280C34F5F5812F90F6CBAA6, 25/02/ 2016, e http:// tvescola.mec.gov.br/tve/video/entrevista-joice-armani-galli, 10/08/2016.

. As línguas estrangeiras como política de educação pública plurilíngue. In: Linguas que botam a boca no mundo: reflexóes sobre teorias e práticas de línguas. Recife: Editora Universitária EDUFPE, 2011, p. 15-36.

- O sistema de avaliação de proficiência em leitura em francês como língua estrangeira nas universidades do Rio Grande do Sul: a prova, os candidatos e o produto de leitura [Tese de Doutorado em Linguística]. Porto Alegre: UFRGS, 2004.

GERALDI, J. W. A aula como acontecimento. São Paulo: Pedro \& João Editores, 2010.

MARCUSCHI, L. A. Da fala para a escrita: atividades de retextualização. São Paulo: Cortez, 2004.

MOITA LOPES, L. P. (org.) Por uma linguistica aplicada indisciplinar. São Paulo: Parábola Editorial, 2006.

PARÂMETROS CURRICULARES NACIONAIS. http://portal.mec.gov. br/seb/arquivos/pdf/pcn_estrangeira.pdf., 21/06/2016.

PNE - Plano Nacional de Educação. http://pne.mec.gov.br/sistema-nacional-de-educacao, 20/02/2016.

PAVIANI, Jaime. Epistemologia prática, 2a ed. Caxias do Sul: UCS, 2013.

Resolução CNE, no 2, jul. 2015. http://portal.mec.gov.br/educacao-quilombola-/323-secretarias-112877938/orgaos-vinculados-82187207/21028-resolucoes-do-conselho-pleno-2015 e http://portal.mec.gov.br/index.php?option=com 
docman\&view=download\&alias=17719-res-cne-cp-002-03072015\&category_ slug=julho-2015-pdf\&Itemid=30192

ROCHEBOIS, C. B. O despertar para a diversidade cultural: ensino de língua francesa a crianças em contextos variados. Fólio: Revista de Letras - Vertentes e Interfaces I: estudos linguísticos e aplicados, v.6, n.2:145-165, jul. I dez. Bahia: Vitória da Conquista, 2014, http://periodicos.uesb.br/index.php/ folio/article/view/4559. (21/04/2016)

RODRIGUES, Fernanda Castelano. Lingua viva, letra morta: obrigatoriedade e ensino de espanhol no arquivo jurídico e legislativo brasileiro [Tese de Doutorado em Linguística pelo Programa de Pós-Graduação em Língua Espanhola e Literaturas Espanhola e Hispano-americana]. São Paulo: Universidade de São Paulo, 2010.

SOARES, Magda. Letramento: um tema em três gêneros. Belo Horizonte: Autêntica, 2001.

\title{
BECOMING A TEACHER OF FRENCH IN BRAZIL: THE EXPERIENCE OF LES CRABES PROJET FOR THE IMPLEMENTATION OF PUBLIC LINGUISTICS POLICIES
}

\begin{abstract}
Reflect on the teaching-learning of foreign languages in Brazil implies discuss linguistic policies. Such reflection invites us to seek an original articulation between public authorities, high education and classroom. From the perspective of language as social practice of interaction, the purpose of this work is to discuss alternative projects to the implementation of plural and inclusive curricula.
\end{abstract}

KEYWORDS: linguistic policies; foreign languages; French.

Recebido em: 31/05/2016 Aprovado em: 09/10/2016 